\title{
DINAMIKA TULISAN ARAB
}

\author{
Tamrin \\ Institut Agama Islam Negeri Palu. \\ Email: tamrintalebe@gmail.com
}

\begin{abstract}
In writing, the Arabic letter is the second letter after the Latin letter which continues to develop and exist today. However, the delay in its development is strongly influenced by the Arab social tradition which prioritizes verbal language and wandering life. In the preIslamic era, especially in the 6th century, linguistic activities were dominated by literature rather than written development. After Islam came the people called for writing the revelations, a spirit of writing began and continued to develope.
\end{abstract}

\section{Key Words : Arabic letters, Revelation, and Verbal Language}

\section{Abstrak}

Dalam penggunaan tulisan, huruf Arab merupakan huruf kedua setelah huruf latin yang terus mengalami perkembang dan eksis hingga saat ini. Namun ketelambatan perkembangannya sangat dipengaruhi oleh tradisi sosial bangsa Arab yang lebih mengutamakan bahasa verbal dan hidup mengembara. Pada masa sebelum Islam khususnya pada abad ke-6, aktifitas kebahasaan didominasi sastra daripada perkembangan tulisan. Setelah datangnya Islam yang menyerukan tulis menulis wahyu, maka dimulailah semangat penulisan dan terus mengalami perkembangan.

Kata Kunci : Huruf Arab, Wahyu, dan Bahasa Verbal 


\section{Pendahuluan}

Berbeda dengan bangsa bangsa lain seperti mesir kuno, Babilonia, dan China. Yang seluk beluk sistem tulisanya bermula ribuan tahun sebelumnya bangsa arab merupakan pendatang yang benar benar terlambat.

Keterlambatan perkembangan ini karena bangsa arab pada umumnya adalah masyarakat pengembara dan tidak begitu memperhatikan bahasa tulis. Mereka hanya bertumpu pada tradisi lisan untuk kepentingan penyebaran berita dan komunikasinya. Pada masa sebelum Islam, atau tepat pada abad ke-6, yang merupakan zaman kesustraan bagi bangsa arab, puisilah barangkali yang paling akrab di hadi mereka,dan merupakan satu satunyabentuk pengungkapan sastra akan tetapi mereka bertumpuk sepenuhnya pada tradisi lisan dalam mengabadikan sajak sajak mereka. Di awal abad ke-7 sesuda lahirnya Islam, Alquran disiarkan pertama kali dikalangan orang Islam tidak melalui lisan namun melainkan dengan tradisi lisan. Skalipun demikian, mereka pun menyadari bahwa perlunya menyalin bahasa dalam bentuk tulisan, dari sini mencul seni menulis indah atau yang kita kenal dengan kaligrafi. ${ }^{1}$

\section{Tulisan Arab Pra Islam}

Huruf Arab berasal dan berkembang dari tulisan dari bangsa bangsa arab sebelumnya. Tulisan Arab berasal dari berkembang tulisan Arami (Aramean), Nabati (Nabaten), dan berakhir menjadi tulisan Hijazi. Tulisan terakhir inilah yang kemudian berkembang di wilaya arab sebelum dakwa Nabi muhammad. Di antara bukti bukti mengukuhkan pendapat ini ialah batu batu yang terukir dengan khat

1 Yasin Hamid Safadi, Islamic Calligraphy yang diterjemahkan ke dalam judul Kaligrafi Islam, oleh Abdul hadi Wm, (Jakarta: Pantja Simpati, 1986), h. 7. 
Arab yang di jumpai sebelum utara hijaz. Khat tersebut diduga mempunyai hubungan dengan Persia dan Roma. ${ }^{2}$

Aram adalah bangsa yang meninggali kawasan mesopotamia dan bercampur dengan bangsa bangsa di wilayah itu. Dalam Alquran surah Al fajr ayat 6-8 disebut sebagai bangsa yang menempati kota Iram (Aram dari Plilar), rumah kaum 'Ad masyarakat wilayah Al Ahqof. Aram terus menjadi penduduk mayoritas dibabel (sekedar disebut Iraq) dan beberapa bagian dari suriah. Sejumlah kerajaan Aramean bermunculan diwilayah tersebut, yang terpenting adalah kerajaan palmyra. Bangsa Aram sendiri terus menyebut diri mereka "Aram", tapi oleh sekeliling mereka dikenal sebagai bangsa Kasdim, Assyaria atau suriah.

Mereka berbicara menggunakan bahasa Semit Barat dari bahasa Aram lama (1100 SM-M 200), namun tulisan mereka menggunakan Abjad Fenisia, yang kemudian dimodifikasikan secara khusus menjadi Abjad Aram. Pada Awal ke-8 SM bahsa tulisan dan Aram bersaing dengan bahsa Semit Timur (Akkadia) dan Tulisan Paku di Asyur, dan selanjutnya menyebar ke timur. Sekitar 800 SM bahasa Aram menjadi Liguafranca dari kekaisaran Neoasyur meskipun terpingirkan oleh Yunani pada periode Helenistik, namun tetap tak tertandingi sebagai dialeg umum diwilayah tersebut sampai pada penaklukan Islam atas Mesopotamia di abad ke-7 Masehi. ${ }^{3}$

Suku Nabatean Adalah salah satu rumpun bangsa Arab yang hidup sebelum masuknya bangsa romawi, mereka adalah sebuah bangsa berawal dari ketutan Nabi Isma'il. Nabi Isma'il diberi karunia dua belas putra, diantara Nebajoth atau Naba dan keturunan

${ }^{2}$ Agung Pirsada, "Sejarah tulisan arab" diakses pada website https://www.academia.edu/5125925/Sejarah_Tulisan_Arab tanggal 12 April 2020

${ }^{3}$ Safadi, Islamic Calligraphy, h. 5. 
nabat Inilah yang akhirnya muncul dinasti Nabatean (600 SM) sampai $50 \mathrm{M}$ ). Mereka kenal sebegai suku pengembara yang berkelana keberbagai penjuru dengan kawanan unta dan domba. Mereka sangat mahir dalam membuat tangki air bawah tanah untuk mengumpulkan air berisi yang bisa digunakan saat mereka bepergian jauh sehingga, dimanapun mereka beradamereka bisa membuat galian untuk saluran air digunakan untuk saluran air guna memenuhi kebutuhan mereka akan air bersih. ${ }^{4}$

Dari tulisan Suriani (Tulisan Neo-aramean), kemudian berevolusi lagi menjadi tulisan Nabatean. Tulisan dikembangkan dari Abjad bahasa arami pada Abad 2 SM. Batu prasasti dalam Abjad Nabatean telah ditemukan di Petra, ibu kota kerajaan Nabatean (tahun 150 SM sampai 100 M), di Syiria dan Damaskus selama 4 abad, abjad Nabatean berevolusi menjadi huruf Arab. ${ }^{5}$

Pendapat senada dengan Nabia Abbott seoran ilmuan yang memiliki otoritas, membuktikan bahwa tulisan bahasa arab berasal dari Nabatean. Dia berpendapat bahwa skrip arab yang digunakan di awal permulaan Islam adalah perkembangan tulisan arab arab sebelum Islam yang secara langsung merupakan pengaruh dari perkembangan tulisan Kerajaan Nabatean Arabi yang muncul pada awal permulaan abad masehi. ${ }^{6}$

Dari tulisan Nabatean yang berkembang di sekitar syiria dan Damaskus pada abad ke-2SM itu, bergerak menuju daerah Anbar di Irak Utara, kemudian ke daerah Hierah, daerah yang terletak antara Najef dan Kufa kemudia bergerak kedaerah Himyiar, Yaman selatan, dari Himyar ke Buq'ah, lalu Tho'if dan akhirnya ke

${ }^{4}$ Pirsada, "Sejarah Tulisan arab"

${ }^{5}$ Safadi, Islamic Calligraphy, h. 7.

${ }^{6}$ Nabia Abbott, The Rise of the North Arabic Acript And Its Kuranic Development, With A Full Description of The Kuran Manuscripts In The Oriental Institute, (Chicago: The University Of Chicago Press, 1938), h.78. 
Mekkah. Dari mekkah kemudian menyebar ke Madinah. Transformasi bahasa Nabatean ke bahasa arab melalui jaur ini lembih lambat dibandingkan melalui jalur pertama. Jenis huruf yang berkembang melalui jalur ini adalah tulisan arab atau khat Hijazi atau Makkih (sekarang dinamai Khatnash).

Bahasa arab sampai ke kota Mekkah melalai jalur ini yang dibawah oleh Basyar Bin malik atau yang lebih dikenal dengan nama Al Kindi. Al kindi adalah saudara Ukaidar, penguasa Daumatul jandal. Al Kindi hijra ke Hierah dan menetap beberapa waktu, dan belajar bahasa arab. Pada suari hari, Al kindi dan Abu Qais melakukan kegiatan bisnis diThaif ditemani pula Ghaylan Bin Salmah At Tsaqafi yan juga belajar bahasa arab dari A Kindi. Kemudian ia mengajarkan bahasa arab disana. Beberapa bangsawan Quraisy memintanya mengajari tata tulis dan ejaan arab, diantarany sufyan Bin umayyah bin Abd syams dan Abu Qois bin Abd Manaf bin Zuhrah, sejak itulah baca tulis maju pesat dikota dagang tersebut. $^{7}$

Ketika tulisan ini sampai Mekkah, orang orang Mekkah mengenal tulisan arab jenis Kufi yang dipelajari dari orang Madinah yang dibawa oleh Harb bin Umayyah pada abad pertama Masehi, sebelum kedatangan Isalam. Disebutkan Bahwa dikalangan suku kaum Quraisy sebelum Islam, hanya terdapat 12 orang saja yang pandai menulis, diantaranya Umar bin Khattab, Ali bin Abu Thalib, Utsman bin Affan dan Yazzid bin Abu Sufian.

\section{Perkembangan Tulisan Arab Di masa Islam}

Pada masa Rasulullah saw, tidak sedikit kebijakan politik yang memberikan nilai positif terhadap perkembangan tulisan.

7 Pirsada, "Sejarah tulisan arab" diakses pada website https://academia.edusejarah tulisan arab diakses tanggal 12 April 2020 
Sejak tahun ke-2, Rasulullah mensyaratkan mengajarkan tulis menulis bagi tawanan yang ingin dibebaskan tanpa membayar tebusan. Isyarat menyempurnakan keberadaan Alquran melalui sikap Rasulullah tersebut adalah bagian yang tidak bisa dipisahkan. ${ }^{8}$ Masyarakat Arab sudah memiliki tulisan sendiri meskipun masih sangat sederhana, yakni dengan model kufi klasik yang tidak memiliki penanda vokal (syarat) dan pembeda konsonan (jumlah dan posisi titik pada huruf yang sama). Selain itu, masih belum dikenal penanda kalimat yang berupa titik, koma, ataupun hiasan tulisan. Tidak dipungkiri bahwa Alquran mempunyai peranan penting dalam perkembangan tulisan arab, yang mana untuk merekam Alquran memaksa memperbaharui tulisan mereka dan memperindahnya. Setelah wafatnya Nabi Muhammad pada tahun $632 \mathrm{M}$, penyebaran Alquran dari mukmin yang yang satu kepada yang lain dengan secara lisan oleh para Huffaz (Mereka yang hapal Alquran dan dapat membaca dalam hati). Pada tahun 633, sejumlah Huffaz ini terbunuh ini terbunuh dalam peperangan yang timbul setelah wafatnya nabi. Ini memberikan peringatan kepada kaum Muslimin, khususnya Umar Bin Khatab, sahabat terdekat Nabi Muhammad Saw yang ditakdirkan menjadi khalifah ke dua setelah wafatnya beliau. ${ }^{9}$

Di saat itu Umar mendesak Khalifah pertama yaitu Abu Bakar As Shidiq agar supaya mengerjakan dan merampungkan penulisan Alquran. Sementara sahabat zaid Bin Sabit yang diperintahkan untuk menyusun dan mengumpulkan wahyu dalam sebuah kitab, yang kemudian ditetapkan olek khalifah ke tiga Utsman Bin Affan pada tahun 651. Dalam masa khalifah inilah terjadi berbagai perluasan dan pembukaan wilayah baru. Konsekwensi dari perluasan wilayah inilah banyaknya orang-orang

${ }^{8}$ Seyyed Hossein Nasr, Islamic Art and Spirituality, terjemahan oleh (Bandung: Mizan, 1993), h. 7.

9 Yasin Hamid Safadi, Islamic Calligraphy, h. 89. 
non Arab yang kemudian masuk kedalam Islam, disamping itu tentu saja meningkatkan interaksi muslim Arab dengan orang non muslim Arab ataupun orang non muslim. Dalam momentum ini pula memungkinkan bahasa dan tulisan Arab semakin tumbuh dan berkembang di kalangan bangsa Romawi, Parsi dan Iraq. ${ }^{10}$ Yang tidak dapat dihindari dari pergumulan budaya ini adalah kekeliruan dalam menentukan jenis huruf dan kesalahan dalam membaca harkat huruf menjadi sebuah fenomena yang tak terhindarkan, tidak hanya dikalangan orang non muslim Arab namun juaga dikalangan orang Arab sendiri, hal ini menjadi kekhawatiran terhadap penguasa kaum muslimin. ${ }^{11}$

Penyusunan kemudian kedalam empat atau lima kitab dan dikirim ke wilayah wilayah Islam yang penting untuk digunakan sebagai naska kitab yang baku. dari sinilah kemudian semua salinan Alquran dibuat, mula mula dalam tulisan mekkah dan madinah, yang merupakan ragam setempat tulisan jazm kemudian dalam tulisan Kuffah. ${ }^{12}$

Pada masa sahabat ini, mushaf al-Qur'an juga ditulis dalam bentuk Kufi Klasik yang tidak memiliki penanda vokal (syakal) dan pembeda huruf (posisi dan jumlah titik pada huruf yang sama) akan tetapi ketebalan dan garis tulisan lebih rata dan serasi. Di masa pemerintahan Ali Bin Abi Thalib (40 H / 661 M), meski tulisan alQur'an masih berbentuk Kufi Klasik, tidak ada perubahan model tulisan, beliau memerintahkan seseorang ahli tata bahasa arab yang bernama Abu Aswad Ad-Duali, untuk menciptakan tanda tanda huruf hidup (nuqat wal harakat), agar tulisan lebih mudah dibaca, khususnya oleh orang orang yang tidak mengerti bahasa arab.

${ }^{10}$ Muhammad Tahir bin abd alqadir alkurdiy almakkiy, Tarikh alkhat Al arabiy wa adabah, (Mesir: Taba' Al awaliy, 1939), h. 54.

${ }^{11}$ Supiaana, M. Karman, Ulumul Qur'an (Bandung: Pustaka Islamika, 2020), h. 238.

12 Yasin Hamid Safadi, Islamic Calligraphy, h. 8. 
Dalam pemberian harkat terhadap Al-Qur'an Abu aswad menunjuk seorang dari suku Al-Qais untuk membantunya dari 30 orang yang di Ajukan Ziyad. Abu Aswad kemudian memerintahkan juru tulis itu mengambil mushaf dan zat pewarna yang berbeda. Dan setiap kali usai satu halaman, Abu Aswad pun memeriksanya kembali sebelum melanjutkan kehalaman berikutnya. ${ }^{13}$

Pekerjaan tersebut disempurnakan oleh beberapa muridnya diantaranya Nasr Ibnu Asm (W. 707), Y ahya Ibnu Ya'mur (W. 708) dan generasi sesudahnya beliau. Maka sempurnahlah tanda tanda huruf hidup yang seperti yang kita lihat, terdiri dari fatha, kashro, dhomma, sukun, tanwin, tasdhid, hamza, tanda mad, dan titik. ${ }^{14}$

Maka sempurnalah tanda tanda Huruf hidup seperti yang kita lihat sekarang, terdiri dari: Fathh, kasrah, Dammah, Sukun, Tanwin, Tasydid, Hamzah, Tanda Mad, dan Titik. Dapat diduga bahwa mushaf Usman ibn Affan dapat ditemukan di museum Turki, Mesir dan Irak. Sedangkan Mushaf Ali ibn Abi Thalib dapat dilihat di museum Irak dan Iran.

Pada akhir masa kekuasaan kekhalifaan Ali bin Abu Thalib, dan awal kekuasaan Bani Umayyah yang dipimpin oleh Mu'awiyyah bin Abi Sufyan, kaligrafi yang Paling banyak dipakai dalam berbagai penulisan adalah jenis Kufih. Orang mulai meninggalkan penulisan Kufih dalam Naskh Naskh dan beralih kepada jenis jenis tulisan lain.Sebab tulisan Kufi dianggap kurang praktis dan kaku, sehingga sulit digoreskan. Sehingga satu satunya Tulisan yang paling banyak digunakan dalam penulisan Naskh hanya tulisan Naskhi.

13 Kamaluddin Marzuki, Ulumul Qur'an, (Bandung: Remaja Rosdakarya, 1994), h. 82-84.

${ }^{14}$ Muhammad Mustafa Al A'zami, The History of the Quranic Text: From Revelation to Compilation (Jakarta: Gema Insani Press, 2005), h. 89. 
Meskipun sebenarnya bahasa Arab telah berkembang jauh sebelum Islam Lahir, tetapi bahasa ini menyebar dengan cepat sejalan dengan perkembangan agama Islam. Khalifah Abdul Malik (685-705 M), dari Bani Umayyah membuat sebuah keputusan politik yang sangat penting dalam bidang ini yaitu dengan menetapkan Bahasa Arab sebagai bahasa resmi seluruh Wilayah Islam. Sehingga perkembangan tulisan pun meluas ke seluruh wilayah kerajaan bersamaan dengan keputusan politik tersebut.

Pada masa Daulah Abasiyyah (750-1258) ditemukan gaya selain Kufih. Pada masa ini ditemukan enam rumusan pokok alaklam al-sittah. Para tokoh awal yang menjadi panutan kaligrafer sampai sekarang muncul pada masa daulah ini seperti Ibnu Muqlah, ${ }^{15}$ Al Bawwab, dan Yaqut Al Musta'shimi.

Awalnya Kaligrafi Islam banyak ditulis di atas kulit dan didaun lontar. Penemuan kertas di China pada pertengahan abad ke$9 \mathrm{M}$ berperan cukup besar dalam perkembangan seni ini. Kertas, selain harganya relatif lebih murah, cukup melimpah, mudah dipotong, dan dari sisi tehnik lebih mudah dibandingkan bahan bahan yang dipakai sebelumnya.

Pada masa Dinasti Mamluk di Mesir (1252-1517), dan Dinasti Safawi di Persia (1502-1736), Muncul tiga gaya baru, yaitu gaya Farisi, gaya Nasta'liq (Merupakan gabungan antara Naskhi, Ta'liq) dan gaya Syikasteh (bentuk terpecah pecah). Kemudian pada Dinasti Utsmaniyah (1281-1924 M) di Turki, lahir model Diwani oleh Ibrahim Munif ( abad ke-15 M/860 H). Kaligrafi kenamaan yang lain adalah Utsman bin Ali (w. 1698 M) yang dikenal sebagai Utsman, dari pengembangan muncul kaligrafer berikutnya Shalha Pasha yang kemudian tercipta gaya Diwani Jali.

${ }^{15}$ Ibnu Muqlah mendapat bimbingan kaligrafi dari Al-Ahwal Qutbah alMuharrir yang merupakan deretan panjang ahli kaligrafi di masa Muawiyah yang masyhur. Dia memiliki peran yang penting dalam pengembangan dan kemajuan jenis tulisan Kursif. Yasin Hamid Safadi, Islamic Calligraphy, 16. 
Khalifah di masa kesultanan Turki Utsmani memang pantas diberi catatan khusus, bukan hanya periode ini yang telah melahirkan gaya-gaya baru Diwani, Diwani Jali, Riq'ah, misalnya, tiga gaya baru yang datang belakangan, akan tapi juga yang menarik adalah besarnya perhatian pemerintah kepada seni ini. Beberapa kesultanan Turki datang dengan penuh ketekunan mendalami kaligrafi kepada seniman khaththath masanya.

Kiblat kaligrafi Islam yang sejak abat $15 \mathrm{M}$ berpindah ke Turki, setelah kokoh di Baghdad sejak abad 9 dan berkembang di Persia sejak abad 14 yang menemukan puncak perkembangan di sana. Rumus rumus baku penulisan Arab tercipta pada periode ini, yang tetap kokoh digunakan sebagai standar hingga saat ini. Negeri Turki selanjutnya menjadi benteng pertahanan terakhir kaligrafi Islam.

Di awal Islam sampai sekarang terdapat 400 lebih gaya, jenis, atau aliran kaligrafi Arab, tetapi yang mampu bertahan dengan penyempurnaan hanya sekitar belasan aliran. Itu pun yang sering digunakan dalam tulisan sebagai komunikasi umum hanya delapan jenis Khat, yakni Naskh, Tsulutsi, Raihani, Diwani, Diwani Jali, Farisi, Riq'ah, dan Kufi. ${ }^{16}$

Olehnya, tulisan Arab merupakan tulisan yang sangat tertingal perkembanganya dari Negara seperti Mesir, China, dan Babilonia. Diantara keterlambatannya, karena bangsa Arab adalah bangsa pengembara, pedagang, dan tidak terlalu memperhatikan tulis menulis. Bangsa Arab adalah bangsa dengan suku di bangsa arab semata bertumpu pada tradisi bahasa dalam berkomunikasi dengan sesama. Dengan berjalanya waktu mulailah muncul tulisan tulisan yang membawa corak khas daerahnya masing masing seperti corak Aramean dan lainnya.

${ }^{16}$ Pirsada, "Sejarah Tulisan arab" diakses pada website https//:academia.edu Sejarah tulisan arab tanggal 12 April 2020. 


\section{Daftar Pustaka}

Abbott, Nabia, The Rise of the North Arabic Acript And Its Kuranic Development, With A Full Description of The Kuran Manuscripts In The Oriental Institute, Chicago: The University Of Chicago Press, 1938.

Al-Akkad, Abbas Mahmud, Ketakwaan Khalifah Ali bin Abi Thalib, Jakarta: Bulan Bintang, 1979.

Ja'far, Rasul, Sejarah Islam, Jakarta: Lentera, 2004.

Kamaluddin Marzuki, Ulumul Qur'an, Bandung: Remaja Rosdakarya, 1994.

Ma'rifat, M. Hadi, Sejarah Alquran, Jakarta: Al-Huda, 2007.

Al-Makkiy, Muhammad Tahir bin abd al-Qadir al-Kurdiy, Tarikh Alkhat Al Arabiy wa Adabah, Mesir: taba' Al awaliy, 1939

Nasr, Seyyed Hossein, Islamic Art and Spirituality yang diterjemahkan dengan judul Spiritualitas dan Seni Islam, Bandung: Mizan, 1993.

Nur Huda, Hafidz \& Sam Muharsafa.Asyiknya Belajar Kaligrafi, cara praktis belajar kaligrafi. Aceh Utara : Afkari Publishing. 2010.

Safadi, Yasin Hamid, Islamic Calligraphy yang diterjemahkan ke dalam judul Kaligrafi Islam, oleh Abdul hadi Wm, Jakarta: Pantja Simpati, 1986.

Supiana, M. Karman, Ulumul Qur'an, Bandung: Pustaka Islamika, 2020 . 
Volume 2, Number 2, Juli- Desember 2020

e-ISSN 2716-4241

ISSN 2723-2344

Thohir, Ajid, Perkembangan Peradaban di Kawasan Dunia Islam, Jakarta: Raja Grafindo Persada, 2004.

Yulika, Febri. Jejak Seni dalam Sejarah Islam. Sumatera Barat: Intitut Seni Indonesia Padangpanjang. 2016. 